\title{
Calculating the Lots of Fortune and Daemon in Hellenistic Astrology
}

\section{Dorian Gieseler Greenbaum}

\begin{abstract}
This paper looks at some of the contributions the Lots of Fortune and Daemon make to the practice of Hellenistic astrology. First, an overview on the role that Fortune and Daimon play for the individual in the Greco-Roman world, including in the perceived fate of an individual, is given. Next, how Fortune and Daimon help to create the system of astrological lots is discussed. The Lots of Fortune and Daemon may be a way of incorporating ideas of personal destiny into astrology, at least in determining length of life, if not in other areas. For this reason, the methods used in their calculation become important. The paper examines variations in these methods and the rationale behind them, what different astrologers say about them, and discusses the way an ancient astrologer (Titus Pitenius, in P. Lond. 130) may have calculated the Lot of Fortune.
\end{abstract}

\section{Introduction}

The position and zodiac sign of the planets in the sky at the moment of casting an astrological chart are clearly central to the practice of astrology. Yet astrologers practicing in the Greco-Roman world relied as well on certain other points considered integral to the interpretation of a chart. These were the lots, and arguably the two most important lots in the Hellenistic astrologer's arsenal were the Lot of Fortune and its reciprocal twin, the Lot of Daemon. The second century astrologer Vettius Valens calls them respectively the 'archetypal' and the 'second' lot. ${ }^{1}$ The Lot of Fortune is most often used in interpretation, and appears in the work of practically every Hellenistic astrologer. We presently have

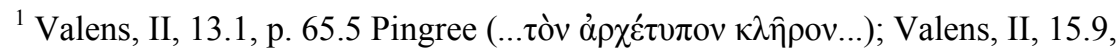

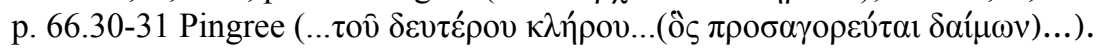

Dorian Gieseler Greenbaum, 'Calculating the Lots of Fortune and Daemon in Hellenistic Astrology', Culture And Cosmos, Vol. 11 no. 2, Autumn/Winter 2007 pp. 163-187.

www.CultureAndCosmos.com 
about 300 extant Greek charts: ${ }^{2}$ of these, 89 (plus two) ${ }^{3}$ calculate the Lot of Fortune. The Lot of Daemon is second, with $33 .{ }^{4}$

The aim of this paper is to examine the Lots of Fortune and Daemon in regard to the ways in which they are calculated by Hellenistic astrologers. Although this might seem a pedantic endeavour, the way the lots are calculated can actually give us information on why astrologers used them. This examination will include the following sections: 1) a (very) short introduction to the concepts of Fortune and Daimon in Hellenistic culture; 2) the components of the lots and their formulae; 3) the astrological doctrine of sect in the calculation of the lots; and 4) the use of the lots in calculating length of life, taking into consideration the importance of sect and the use of the luminaries in the calculation of these lots. All of these will, I hope, help to show us some reasons why these lots were considered to be so important to Hellenistic astrologers.

\section{A Brief Overview of Fortune (Tychē) and Daemon (Daimōn)}

We may begin by asking some questions: why Tychē and Daimōn? What is the connection between them, and why are they so important? We may find some answers by looking at Alexandria and its culture. It was here that cults of Fortune (Agathe Tyche) and Agathos Daimon became well-

\footnotetext{
${ }^{2}$ I have drawn from the collections in O. Neugebauer and H. B. Van Hoesen, Greek Horoscopes (Philadelphia, 1959, repr. 1987) [hereafter Greek Horoscopes]; A. Jones, Astronomical Papyri from Oxyrhynchus (2 vols, Philadelphia, 1999) [hereafter Jones, Astronomical Papyri]; D. Baccani, Oroscopi Greci: Documentazione papirologica, Ricerca Papirologica I, ed. R. Pintaudi (Messina, 1991); T. de Jong and K. A. Worp, 'A Greek Horoscope from 373 A.D.', Zeitschrift für Papyrologie und Epigraphik (1995), vol. 106, pp. 23540; and T. de Jong and K. A. Worp, 'More Greek Horoscopes from Kellis (Dakhleh Oasis)', Zeitschrift für Papyrologie und Epigraphik (2001), vol. 137, pp. 203-14. Some of these charts are quite fragmentary.

${ }^{3}$ I have also included one Demotic (Egyptian) chart and one chart of Dorotheus which, though only in the Arabic translation, can be supposed to have originally been in Greek.

${ }^{4}$ Two charts, both in Greek Horoscopes, nos 95 and 137, also calculate 'lots'. However, I think they may be referring to places, not lots, because they conform to no recognised formula for either the Lot of Fortune or the Lot of Daemon. Thus I have not included them in the totals.
} 
established, starting in the second century BCE. ${ }^{5}$ Tyche and Daimon as they appear in Alexandria have strong connections and assimilations to native Egyptian deities like Shai and Renenet, as well as to Isis and the Greco-Egyptian creation Sarapis; these pairs are linked both iconographically and religiously. ${ }^{6}$ In addition to general cults of Agathe Tyche and Agathos Daimon, the idea of a personal tuchē and daimōn also develops further at this time. ${ }^{7}$

Plutarch popularised the notion of a personal daimōn and tuche in his Parallel Lives, where each biographical subject is either aided or not by fortune and a correspondingly good or bad, strong or weak, daimōn. ${ }^{8} \mathrm{He}$ went on, in his Moralia, to lay out a comprehensive daimonology which

\footnotetext{
${ }^{5}$ P. M. Fraser, Ptolemaic Alexandria (3 vols, Oxford, 1972) [hereafter Ptolemaic Alexandria], here vol. 1, pp. 241-42. The Tychaion in Alexandria is described by (Ps.)-Libanius, Descriptiones, 12.25: see C. E. Visser, Götter und Kulte im ptolemaïschen Alexandrien (Amsterdam, 1938), p. 99, for this text. The Agathos Daimon as a protective city god may be found in the late period tale The Potter's Oracle, which only survives in Greek but which was clearly based on an Egyptian model. See L. Koenen, 'Die Prophezeiungen des "Töpfers"', Zeitschrift für Papyrologie und Epigraphik (1968), vol. 2, pp. 178-209. English translations have been done by Stanley M. Burstein, ed. and tr., The Hellenistic age from the battle of Ipsos to the death of Kleopatra VII (Cambridge, 1985), pp. 136-39; and Allen Kerkeslager, 'The Apology of the Potter: A Translation of the Potter's Oracle', in Jerusalem studies in Egyptology, ed. I. Shirun-Grumach (Wiesbaden, 1998), pp. 67-79.
}

${ }^{6}$ Although the cults linking the Tyche and Daimon date from the $4^{\text {th }}$ century BCE, they are especially prevalent in Ptolemaic and Roman Egypt, where the Egyptian assimilations occur. See Ptolemaic Alexandria, vol. 1, pp. 209-11, for Daimon and Tyche in this period. See also the images collected by Françoise Dunand in Lexicon Iconographicum Mythologiae Classicae (Zurich \& Munich, 1981-1999), vols 1.1, 1.2 (1981), s.v. Agathodaimon; Angeliki Kosmopoulou, The Iconography of Sculptured Statue Bases in the Archaic and Classical Periods (Madison, WI, 2002), Plate 45 (commentary on pp. 189-90); Charles M. Edwards, 'Tyche at Corinth', Hesperia (July 1990) vol. 59, no. 3, pp. 529-542, here p. 539 and Plate $87 \mathrm{~b}$.

${ }^{7}$ See Ptolemaic Alexandria, vol. 1, pp. 241-43.

${ }^{8}$ For daimōn (as well as tuchē) in the Lives, see F. E. Brenk, In Mist Apparelled: Religious Themes in Plutarch's Moralia and Lives (Leiden, 1977), here Chapter 8, pp. 145-83. 
166 Calculating the Lots of Fortune and Daemon in Hellenistic Astrology

explained how daimones influence and act upon individual lives. ${ }^{9}$ He also devoted much thought to the workings of tuche in his essays. ${ }^{10}$

The idea of a personal daimōn was known in Greece at least since the time of Plato; Socrates' guiding daimōn is well-known in the dialogues. We find some references to an individual personal daimōn beginning around the fourth or third century BCE. For example, one Posidonius, who consulted an oracle of Apollo at Telmessus, was told that he should pay homage to 'the Agathos Daimon of Posidonius and Gorgis' (his own and his wife's daimones). ${ }^{11}$ Both Fortune (Tuchē) and Daemon (Daimōn) are, in the culture of the late antique Greco-Roman world, given great power in the determination of human fate. Cults of Agathe Tyche and Agathos Daimon arose, as early as the fourth century BCE, to propitiate these deities, and they were still flourishing when the Hellenistic form of astrology came to prominence. (In Roman Egypt, children were even named 'Agathos Daimon'.) ${ }^{12}$ Pliny, in his Natural History, laments the ubiquity of Fortune in world opinion, and even explicitly calls her the

\footnotetext{
${ }^{9}$ The most important essays for the elucidation of his concepts on the daimōn are De defectu oraculorum, De facie quae in orbe lunae apparet and De genio Socratis. For a study of Plutarch's daimonology, see Frederick Brenk, In Mist Apparelled: Relgious Themes in Plutarch's Moralia and Lives (Leiden, 1977); see also idem, 'In the Light of the Moon: Demonology in the Early Imperial Period', Aufstieg und Niedergang der römischen Welt (II, 16.3, Berlin, 1986), pp. 2068-2145 (for our purposes, esp. pp. 2117-45); and G. Soury, La démonologie de Plutarque (Paris, 1942).

${ }^{10}$ See, e.g., De fortuna, De fortuna Romanorum, De Alexandri magni fortuna aut virtute.

${ }^{11}$ G. Sfameni Gasparro, 'Daimôn and Tuchê in the Hellenistic Religious Experience', in P. Bilde, T. Engberg-Pedersen, L. Hannestad and J. Zahle, eds, Conventional Values of the Hellenistic Greeks (Aarhus, 1997), pp. 67-109, here p. 89 and nn. 172-173.

${ }^{12}$ Ptolemaic Alexandria, vol. 1, p. 209.
} 
'lot' (sors) which 'takes the place of god'. ${ }^{13}$ Polybius mentions Tyche as a potent force in the rise and fall of nations. ${ }^{14}$

It does not seem unusual, then that the culturally important Fortune and Daimon were assimilated into astrology - after all, the interpretation of the astrological chart is supposed to reveal just such fortunes for its 'natives'. We certainly see one way they have been incorporated in the names of the astrological places: the fifth and sixth are Good Fortune and Bad Fortune, and the eleventh and twelfth Good Daimon and Evil Daimon.

Yet these assignments were clearly not enough to take the entire scope of Fortune and Daimon, as related to the individual, into account. The lots are a system which, since it mostly uses the Ascendant as a projection point, ${ }^{15}$ emphasises the particular rather than the general astrological correlation to the individual. To point up the personal outcomes of Fortune and Daimon on the individual, the two most important lots, therefore, became the Lot of Fortune and the Lot of Daemon. With the incorporation of Fortune and Daimon into the personal system of lots, astrology thus provided a way for an individual to discover the effects of a personal tuche and daimōn astrologically.

In addition, there is a strong sense of destiny linked to these lots; both Fortune (Tuchē) and Daemon (Daimōn) are, in the culture of the late antique Greco-Roman world, given great power in the determination of human fate. By the second century $\mathrm{CE}$, we find essays on fate which consider the power of both Tyche and Daimon. ${ }^{16}$ In the Tabula Cebetis, which may be earlier but was popular in the second century, Daimon guides the entry into life, which contains a Tyche who gives and takes

\footnotetext{
${ }^{13}$ Pliny, Historia Naturalis, II, v.22-26. ' ‘..toto quippe mundo et omnibus locis omnibusque horis omnium vocibus Fortuna sola invocatur ac nominatur....' (v.22); '...ut sors ipsa pro deo sit, qua deus probatur incertus.' (v.23).

${ }^{14}$ For a discussion of Fortune in Polybius, see P. Shorey, 'Tv́ $\chi \eta$ in Polybius', Classical Philology (1921), vol. 16, no. 3, pp. 280-83.

${ }^{15}$ The Ascendant is arguably the most personal point in the chart, since it marks the moment of birth zodiacally at the intersection of the horizon and ecliptic.

16 E.g., Ps.-Plutarch, On Fate; Maximus of Tyre, Orations, esp. 5, 8, 9, 13; Apuleius, De deo Socratis, De Platone; Alexander of Aphrodisias, On Fate.
} 
away fortune for those entering. ${ }^{17}$ And for the daimon and allotment of fate, we need turn no further than the Myth of Er in Book X of Plato's Republic, where souls choose the daimōn who is in charge of their destiny, and this choice is ratified by the three Moirai. In the Laws (876e$877 b$ ) we see Tyche and Daimon together, represented as responsible for a man's life - Tyche is the bad fortune under which he tries to kill someone, and Daimon the guardian who keeps the wound from being fatal (for which, Plato says, he should be banished, not executed). ${ }^{18}$ (In astrology, the Lots of Fortune and Daemon when afflicted are associated with violent death and banishment.) ${ }^{19}$ So there may be a sense that the Lots of Fortune and Daemon, which are the most important lots in interpretation and prediction, are particularly capable in delineating the fate (and the providence) which is endowed to their recipients.

\section{The Lots and their Luminaries}

The planets used in the calculations of these lots are those known in astrology as the luminaries, the Sun and the Moon. The Moon is associated with the body, and the Sun with the mind, the soul and spirit. By a certain amount of assimilation, the two lots also gain these associations. The Moon was traditionally the boundary between heaven

\footnotetext{
${ }^{17}$ See J. T. Fitzgerald and L. M. White, The Tabula of Cebes (Society of Biblical Literature, Texts and Translations Graeco-Roman Religion Series, Chico, CA, 1983). There are a number of motifs in this work which may have other astrological implications, in addition to its obvious Platonic correspondences.

18 'So let our written law concerning wounding run thus: -If any man intends on purpose to kill a friendly person - save such as the law sends him againstwounds him, but is unable to kill him, he who has done this on purpose and gave the wound does not deserve to be pitied; rather he is to be regarded exactly as a killer and must be compelled to submit to trial for murder; yet out of respect for

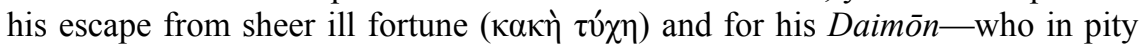
alike for him and the wounded man saved the wound of the one from proving fatal and the fortune and crime of the other from proving accursed - in gratitude to this Daimōn, and in compliance therewith, the wounder shall be relieved of the death-penalty, but shall be deported for life to a neighbouring State, enjoying the fruits of all his own possessions.' (Translation of R. G. Bury slightly modified.)

19 See, e.g., the fifth consideration in the tabular investigation of Rhetorius, $C C A G 8 / 4$, pp. $120-22$.
} 
and earth - the 'sublunary sphere' as opposed to the celestial home of the gods. Daimones are also associated with the Moon, for example in Plutarch, where they are said to live on the Moon, ${ }^{20}$ the better to keep an eye on the affairs of humans. The Moon is also the traditional planet associated with Fortune, as it is a literal representation of the changeability of life with its cycles of waxing and waning. The astrologer Antiochus of Athens explains: 'The Moon, being nearer to the earth, receiving the effluences of the stars above her and ministering to all earthly things, rules over the entire human body. ${ }^{21}$ Valens writes: 'For cosmically the Moon is fortune and body and breath, since she is close to the earth and sends her effluence into us, and she brings about something similar as she has authority over our body. ${ }^{, 22}$

The Sun, on the other hand, is connected to the Daimon, in that it is metaphorically associated with mind and spirit. As Valens says, 'the allseeing Sun, being fiery and a light of the mind, instrument of the soul's sense-perception, signifies ... intelligence, practical and intentional mind.... ${ }^{23}$ And, he adds, 'The Sun, which is cosmically mind and spirit (daimon) on account of his own activity and lovely nature, stirring up human souls for undertakings, is established as a cause of action and movement. ${ }^{24}$

We can see some correlations between the Moon and the Lot of Fortune, and the Sun and the Lot of Daemon, in the following table:

${ }^{20}$ Cf. De facie quae in orbe lunae apparet, $944 \mathrm{~b}-945 \mathrm{~d}$.

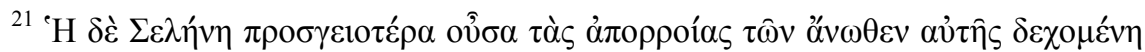

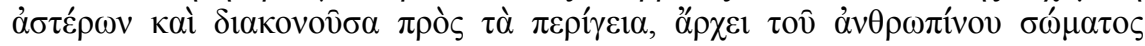

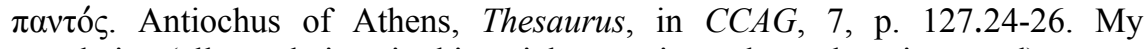
translation (all translations in this article are mine unless otherwise noted).

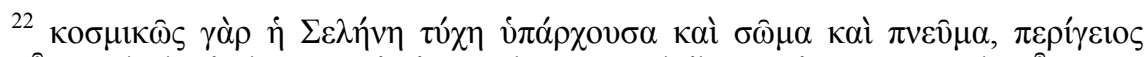

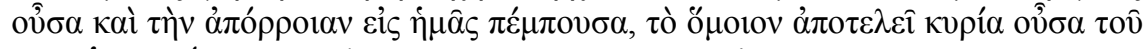

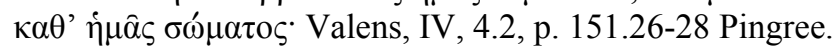

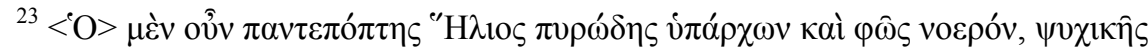

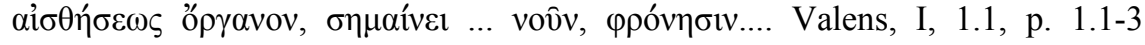
Pingree.

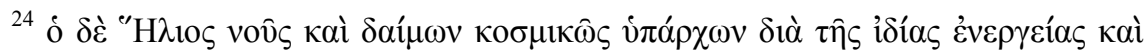

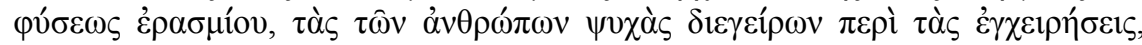

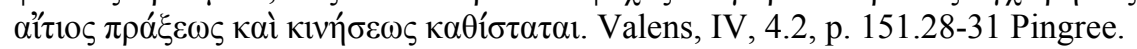


170 Calculating the Lots of Fortune and Daemon in Hellenistic Astrology

Table 1. Attributions of the Sun/Lot of Daemon and the Moon/Lot of Fortune $^{25}$

\begin{tabular}{|c|c|c|c|}
\hline Sun & Lot of Daemon & Moon & Lot of Fortune \\
\hline breath & soul & body & human bodies \\
soul & intentional mind & mother & actions in life \\
movement & character & conception & sufferings of soul \\
mind & power & fortune & companionship \\
light of the mind & worth & breath & reputation \\
intentional mind & reputation & an eye & fortune \\
spirit (daimôn) & pronoia & \\
action & religious rites & & \\
vision, an eye & intended plans & & \\
oracular response & advice & & \\
of gods & mental activity & & \\
soul's sense- & & & \\
perception & & & \\
\hline
\end{tabular}

The luminaries, the Sun and Moon, were considered the most significant bodies in astrological interpretation. They receive this importance from their astronomical prominence, their clear causal connections to life on earth and particularly, I suspect, from the light they provide. (Their importance in Egyptian and Babylonian cosmology, which influenced the doctrines/principles of Hellenistic astrology, also should not be discounted.) Even though they are treated as 'planets' in astrology, ${ }^{26}$ they are also set apart from the other five visible planets, probably - at least partially - because of the light they give. (Note that in Plato's planetary scheme in the Myth of Er [616e-617a], the sphere of the Sun is the 'brightest' and that of the Moon 'reflected light'.) In the planetary listings for both the non-literary and literary extant Greek charts, the luminaries are usually listed together, before or after the other planets. $^{27}$ Demotic charts also seem to follow these kinds of

${ }^{25}$ These attributions are drawn from Vettius Valens (I, 1; II, 20; IV, 4 and 25; IX, 2), Antiochus of Athens (CCAG 1, p. 160; $C C A G$ 7, p. 127), Paulus (ch. 23) and Olympiodorus (ch. 22).

${ }^{26}$ In that they 'wander' as the other planets do, unlike the 'fixed stars' which move only extremely slowly (approximately $1^{\circ}$ every 72 years) against the backdrop of the ecliptic.

${ }^{27}$ Greek Horoscopes, p. 164. 
arrangements. ${ }^{28}$ Babylonian charts usually list the Moon first and the Sun next, before the rest of the planets. ${ }^{29}$

The fact that the Lots of Fortune and Daemon are aligned and formed from the luminaries may help account for their importance and in turn emphasise the importance of the luminaries. In Valens, they are used both in elaborate time-lord systems and in the predictive technique known as profections. In Manilius and in Valens, the Lot of Fortune and places from it have much interpretive significance. In Paulus Alexandrinus and Olympiodorus, his commentator, Fortune and Daemon are listed first in the chapters on lots; indeed, Olympiodorus points out that they are crucial to the creation of the other planetary lots. ${ }^{30}$

\section{Calculating the Lots of Fortune and Daemon}

In the formulae for the Lots of Fortune and Daemon, we know that Ptolemy is the exception in not taking the sect of the chart into account. The common formulae are: for the Lot of Fortune, take the arc from Sun to Moon in a diurnal chart, and the arc from Moon to Sun in a nocturnal one, and project this arc from the Ascendant to find the position of the lot. ${ }^{31}$ We can state this mathematically as:

$$
\text { Asc }+ \text { Moon }- \text { Sun (D) or Asc }+ \text { Sun }- \text { Moon (N) }
$$

${ }^{28}$ M. Ross, Horoscopic Ostraca from Medinet Mâdi ( $\mathrm{PhD}$ thesis, Brown University, Providence, 2006), pp. 24-25.

${ }^{29}$ The Babylonian Moon god was considered to be of primary importance, which is probably why the Moon is listed first. The extant chart listings can be found in F. Rochberg, Babylonian Horoscopes (Transactions of the American Philosophical Society, 88, pt. 1, Philadelphia, 1998). While there is no reason to believe that the order will change in charts discovered in the future, it is likely that more Babylonian horoscopes will be discovered, considering the large amount of unpublished and only partially catalogued cuneiform tablets. For example, Francesca Rochberg has told me recently (private communication, 7 May 2007) of a newly-found duplicate of Text 9, the horoscope of Anu-bēlšunu, in Babylonian Horoscopes, pp. 79-81.

${ }^{30}$ Olympiodorus, Commentary on the Introduction of Paulus, ch. 22, p. 47.5-10 Boer; see also D. Greenbaum, trans., Late Classical Astrology: Paulus Alexandrinus and Olympiodorus, with the Scholia from Later Commentators (Reston, VA, 2001), p. 104.

${ }^{31}$ We shall discuss below one extant chart which seems not to do this. 
172 Calculating the Lots of Fortune and Daemon in Hellenistic Astrology

The arc is determined from the sect luminary - the Sun by day and the Moon by night. For the Lot of Daemon, the formula reverses:

$$
\text { Asc }+ \text { Sun }- \text { Moon (D) or Asc + Moon }- \text { Sun (N) }
$$

Figure 1. The Lots of Fortune and Daemon in a Diurnal Chart

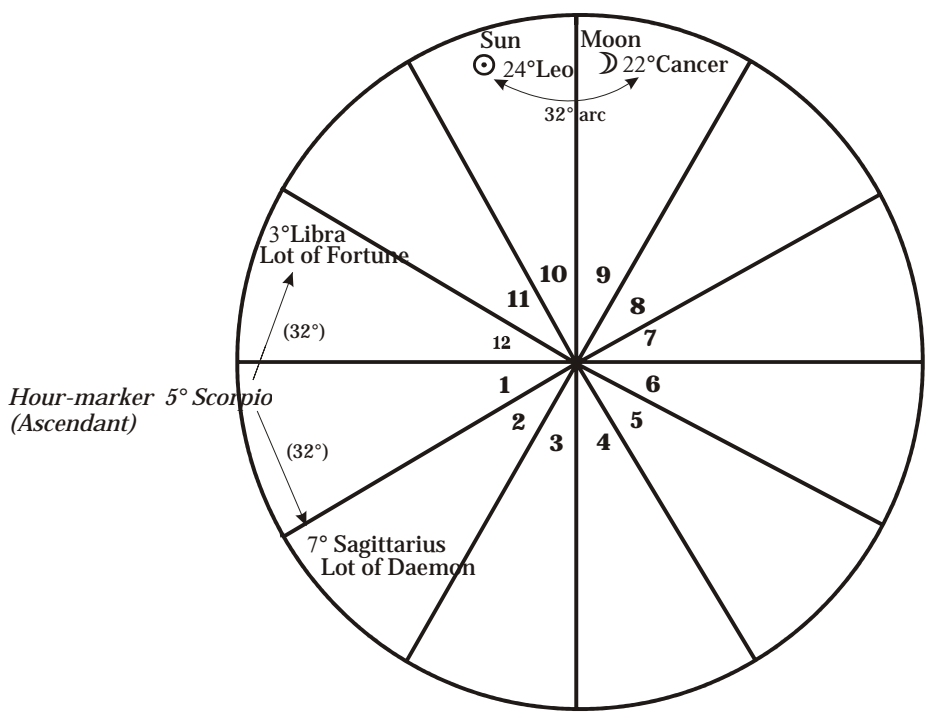

Through the incorporation of the sect requirement in the formula, the relationship between the lots is visually seen, as they become mirror images of each other. In addition, they are linked mathematically via their equal proportion from the Ascendant. We shall now turn to an investigation of sect in lot calculation.

\section{Lot Calculation and the Doctrine of Sect}

Even though the vast majority of Hellenistic astrologers change their calculations of the lots to align with the day or night sect of the chart, there has been some confusion over this doctrine in the tradition (both by scholars and by the astrologers themselves). By investigating this issue, we shall try to find a small amount of clarity by 1) laying out the unclear places in the tradition and 2) suggesting reasons for the confusion. I think this issue is relevant to the Lots of Fortune and Daemon, because I believe it has some bearing on the way that the lots are used in practice, 
on the importance of the strength of the Sun and Moon, and ultimately on the philosophy behind the lots.

There is an interesting chart in Greek Horoscopes that will serve nicely as a jumping-off point for this investigation. Though like most extant non-literary charts, it contains little in the way of interpretation (a competent astrologer would have no need to write down his interpretations before speaking to his client), it certainly focuses our attention on the problem of lot calculation and the doctrine of sect.

This enigmatic chart is No. 81 in Greek Horoscopes. ${ }^{32}$ It mentions a Lot of Fortune as well as a 'first lot' and calculates it according to a recognised formula. The chart has been calculated by a certain 'Titus Pitenius', is dated 31 March $81 \mathrm{CE}$ and is cast for the 'third hour of the night' ${ }^{33}$ It states that 'ignorance' will cause some to place the Lot of Fortune in Libra instead of Sagittarius: 'The Lot of Fortune, in both the zodiac sign and trigon [i.e. triplicity] of Zeus, will fall in reverse (anapalin): which some, through ignorance, will give to Libra: nevertheless Aphrodite has, in turn (palin), a lot, namely the $1^{\text {st: }}$ good luck! ${ }^{34}$

\footnotetext{
${ }^{32}$ P. Lond. 130, pp. 21-28. I am indebted to Stephan Heilen, Deborah Houlding and Robert Hand for helpful comments on this section. I am particularly grateful for Heilen's close inspection of and suggestions for the translations.

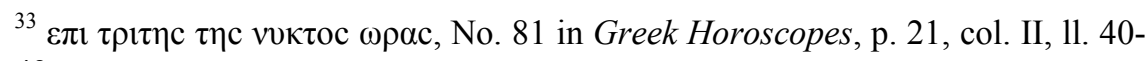
43.

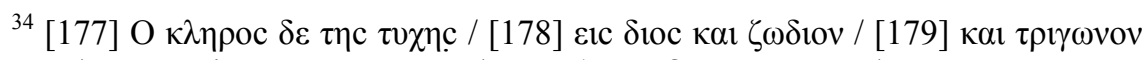

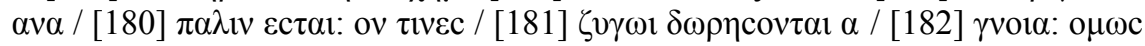

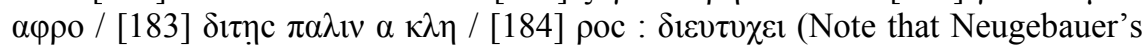
translation does not translate " " 1 st" lot' in line 183 , but I clearly see an ' $\alpha$ ' in the transcript.) The arc between the Sun and the Moon here is ca. $29^{\circ}$. Depending on the direction this amount is projected from the Ascendant, the lot(s) will fall either in Libra $19^{\circ}$ or Sagittarius $17^{\circ}$. For a brief discussion of this chart, see B. L. Van der Waerden, 'Greek Astronomical Calendars IV. The Parapegma of the Egyptians and their "Perpetual Tables", Archive for History of Exact Sciences (1985), vol. 32, pp. 95-104, here pp. 100-101. A. Bouché-Leclercq, L'astrologie grecque (Paris, 1899) [hereafter L'astrologie grecque], p. 291, n. 1, also mentions this particular chart. Neugebauer and Van Hoesen have pointed out some of his interpretational errors (Greek Horoscopes, pp. 23, 25, 28). BouchéLeclercq assumes that Titus Pitenius knew Nechepso by his use of the word anapalin. But see below for more on this issue.
} 
174 Calculating the Lots of Fortune and Daemon in Hellenistic Astrology

Figure 2. Chart No. 81 in Greek Horoscopes

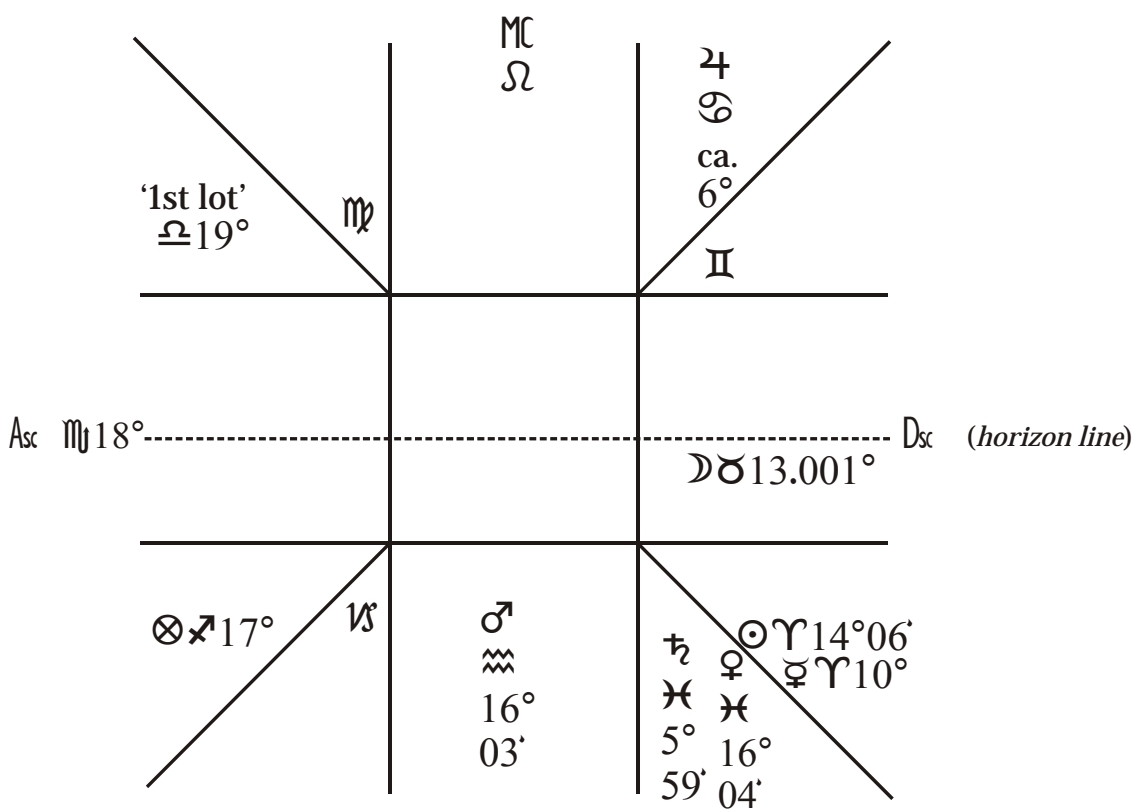

It appears from this description that at the very least, the calculation of the lots was rather fluid at this time, and that there was disagreement on exactly how to do it. It is interesting that Titus Pitenius, the astrologer, has used the words ' $\alpha \dot{\alpha} \alpha \dot{\pi} \alpha \lambda v_{v}$ ' in the first phrase and ' $\pi \alpha{ }^{\lambda} \lambda v$ ' in the third. Pitenius may be echoing the Egyptians Nechepso and Petosiris ${ }^{35}$ here in using anapalin and palin, which have multi-valent meanings, thus keeping the intended meaning vague. ${ }^{36}$ However, let us look at some interpretive possibilities. Using 'in reverse' and 'in turn' could suggest that he is not denying the existence of two lots formed from the soli-lunar arc, but that he disagrees with the method some use in their calculation. Or, he could be stressing the disagreement among astrologers as to how to calculate the one lot. These astrologers would place the ' $1^{\text {st }}$ lot' in

${ }^{35}$ A legendary Egyptian king and his priest, to whom astrological writings are ascribed. Their writings (surviving only in fragments), alas, are often enigmatic and unclear, as we shall see.

${ }^{36}$ We shall see variations of Nechepso-Petosiris quotations using these words and others below. 
Libra, though Pitenius does not believe that is correct. By calling the lot in Libra the ' $1{ }^{\text {st }}$ lot', is he tacitly acknowledging a Lot of Daemon (whose formula is the reverse of the Lot of Fortune)? $?^{37}$ The use of the term ' $1{ }^{\text {st }}$ lot' is suggestive, but unfortunately we can only speculate on this point. Even though we know that the Lot of Fortune is called 'archetypal' (from which we could extrapolate the idea of 'primary' or 'first'), and the Lot of Daemon is called the 'second lot', we do not really have any proof here that Pitenius is acknowledging two lots, only two possible formulae. And it seems that the formula he prefers is what Ptolemy will use roughly fifty years in the future, which is the diurnal formula for both day and night charts, not making the reversal of other authors. ${ }^{38}$ This will place the lot in Sagittarius.

I would now like to explore two possible scenarios for Pitenius's comments. The first has to do with his interpretation of the correct formula to use for the Lot of Fortune. This is the formula of NechepsoPetosiris, which is mentioned by various authors (and quoted by Vettius Valens). ${ }^{39}$ (We may note that at the beginning of this chart analysis, Pitenius mentions 'the Egyptian men of old', ${ }^{40}$ so he could have been familiar with the writings of Nechepso-Petosiris.) The formula, unfortunately, is not clear ${ }^{41}$ (even Valens uses the word 'mysteriously' in quoting it):

${ }^{37}$ Chart Nos 95 and 137 in Greek Horoscopes mention a 'first' and/or a 'second' and even 'third' lot (No. 137 calls them 'fortune' but No. 95 does not). In these cases, the lot's calculated position does not match with the usual formulae for the Lots of Fortune and Daemon (even though the 'first lot' in No. 95 is called 'Agathos Daimon', it may refer to the place in which the lot falls, not the name of the lot); still, the lots are numbered like the one in No. 81. 'Deluxe Horoscope No. 4277' in Jones, Astronomical Papyri, vol. 2, pp. 424-27, also numbers the lots, but assigns them consecutively to the lots of Fortune, Daemon, [Eros] and Necessity.

${ }^{38}$ The earliest reference may be in Manilius, Astronomica, 3.176-200, where the formula for the Lot of Fortune reverses for a nocturnal birth.

${ }^{39}$ See Valens, II, 3.1 and IX, 2.8 for two versions (quoted in this paragraph); and then III, 11.4 for further comments on another passage of Nechepso-Petosiris dealing with the same subject (quoted below, p. 185).

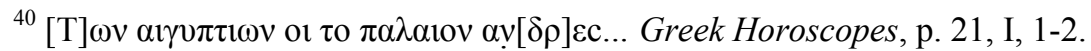

${ }^{41}$ As I said above, note 35, the fragments of these authors are often enigmatic, which contributes to the reasons for confusion I mentioned earlier. Let me note

Culture and Cosmos 
176 Calculating the Lots of Fortune and Daemon in Hellenistic Astrology

... I will go back to the Lot of Fortune, which is a most necessary and potent place, as the king ${ }^{42}$ mysteriously showed beginning ${ }^{43}$ in the $13^{\text {th }}$ book, saying: 'Next it will be necessary, for those born in the day, to count precisely all the way through from the Sun to the Moon, and to place an equal amount in the opposite way [empalin] from the Hour-marker'..... ${ }^{44}$

First, note that the quotation says, 'born in the day', implying that there is another formula for a night birth. But what is the diurnal formula? This version of the text seems to say that one should count from the Sun to the Moon in zodiacal order, and then to reverse that order (i.e. go in diurnal

at this point that we are treading a bit through a minefield in attempting to elucidate Nechepso and Petosiris (I fear that Bouché-Leclercq has only muddied the waters in his sarcastic attempt to explain lot doctrine; see L'astrologie grecque, pp. 289-94). Certainly, as Stephan Heilen remarked (private communication, 10 Aug 2007), the writings of the Egyptians are 'notoriously obscure and difficult to understand', due to their ambiguous terminology. In addition, their original verses (iambic trimeter) were transmitted in prose paraphrase by Valens, Firmicus and others, which further compromised their clarity (E. Riess, in his edition of the fragments [see below, n. 43] includes commentary and reconstruction of the verses, e.g. pp. 333, 364, 374 and 376.) However, by persevering in this investigation of the Lot of Fortune, quotation by quotation, we may begin to acquire a little more understanding of the nature of this doctrine (and open the door to further interest in this issue).

${ }^{42}$ Nechepso.

${ }^{43}$ Evó́p $\chi 0 \mu \alpha 1$, whose first meaning is 'begin the offering in a sacrifice'. Could Nechepso be using that word deliberately here to stress the religico-ritualistic nature of his advice?

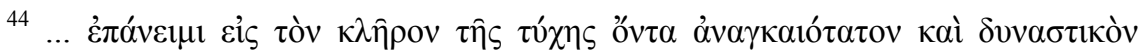

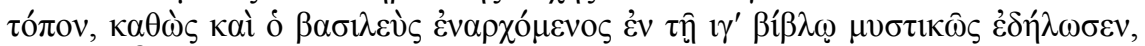

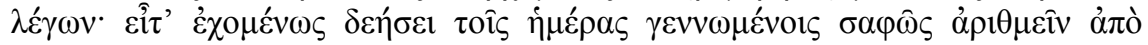

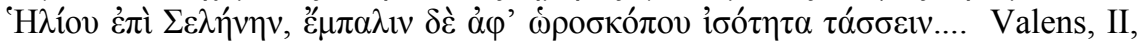
3.1, p. 58.15-19 Pingree. I am, in this instance, trying to avoid the accretions which have been made by later interpreters such as the scholiast of Ptolemy (see E. Riess, ed., Nechepsonis et Petosiridis fragmenta magica, in Philologus, Suppl. Bd. 6, pt. 1, Göttingen, 1892, pp. 325-394, here pp. 363-64) who, after all, was commenting on Ptolemy (who is obviously later than Pitenius), and stick to a chronologically closer rendition of Nechepso-Petosiris. 
order, or subtract) when applying it to the Ascendant (Interpretation \#1: see Figure 3a). However, another variant of this text suggests something different:

Not aimlessly does Petosiris say, concerning the sympathy ${ }^{45}$ of the Sun and Moon in the Definitions: 'Either you will find the [sc. sympathy] from Sun to Moon and the equal amount from the Hour-marker, or from Moon to Sun and the equal amount having fallen in from the Hour-marker by the same [method].... And also the king, in the beginning of the $<13^{\text {th }}>$ book said: "Next it will be necessary to count precisely all the way through from Sun to Moon or in the opposite way [empalin] (others read: 'in reverse' [anapalin]), to make an equal amount from the Hour-marker. ${ }^{46}$

The word order here seems to me to be saying more clearly that what is meant is the reversal of the order of the luminaries, not the direction from the Ascendant (Hour-marker). So one would count from the Sun to the Moon in zodiacal order (or the reverse, from Moon to Sun, for a nocturnal chart), and then project from the Ascendant the same amount, also in zodiacal order (Interpretation \#2: see Figure 3b) ${ }^{47}$

\footnotetext{
${ }^{45}$ By 'sympathy', Petosiris means the way that the lots, by using proportions between the Sun, Moon and Ascendant, show the sympathy of the newborn child in proportion with the cosmos. The previous passages discuss this.

46 The complete passage is at Valens, IX, 2.7-8, p. 319.17-26 Pingree:

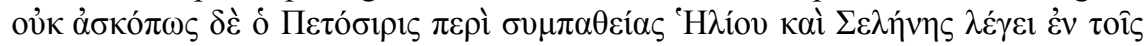

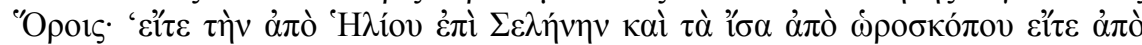

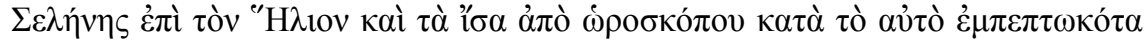

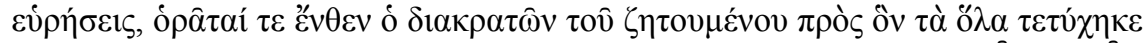

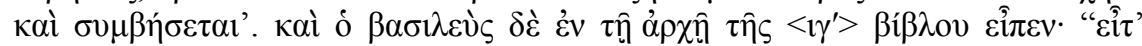

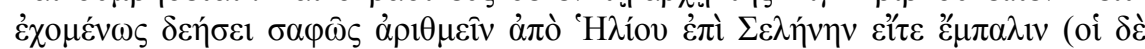

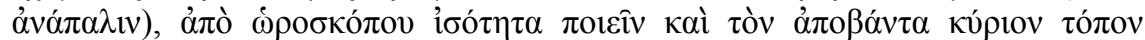

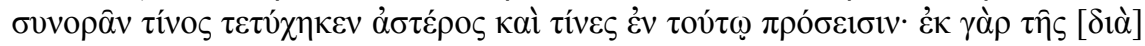

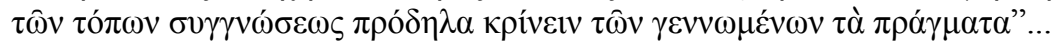

${ }^{47}$ In practice, this is what almost all ancient astrologers do (see the numerous examples in Valens, and the non-literary charts which calculate the Lot of Fortune in Greek Horoscopes).
} 
178 Calculating the Lots of Fortune and Daemon in Hellenistic Astrology

Figure 3a.

Nechepso-Petosiris Interpretation \#1

(Diurnal Chart)

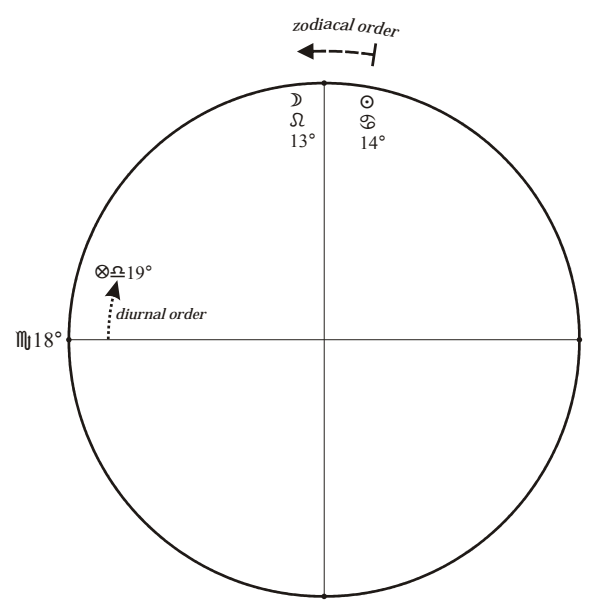

Figure 3b.

Nechepso-Petosiris Interpretation \#2

(Diurnal Chart)

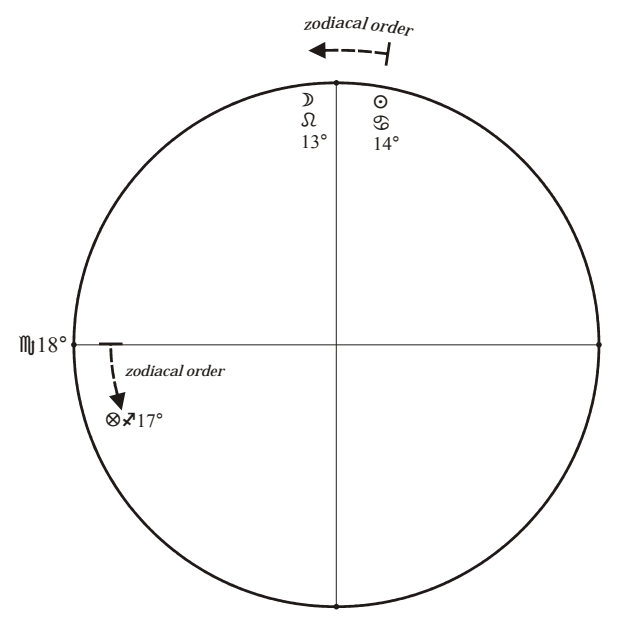

Culture and Cosmos 
Figure 4. Pitenius Interpretation of Nechepso-Petosiris, Nocturnal Chart, following Interpretation \#1

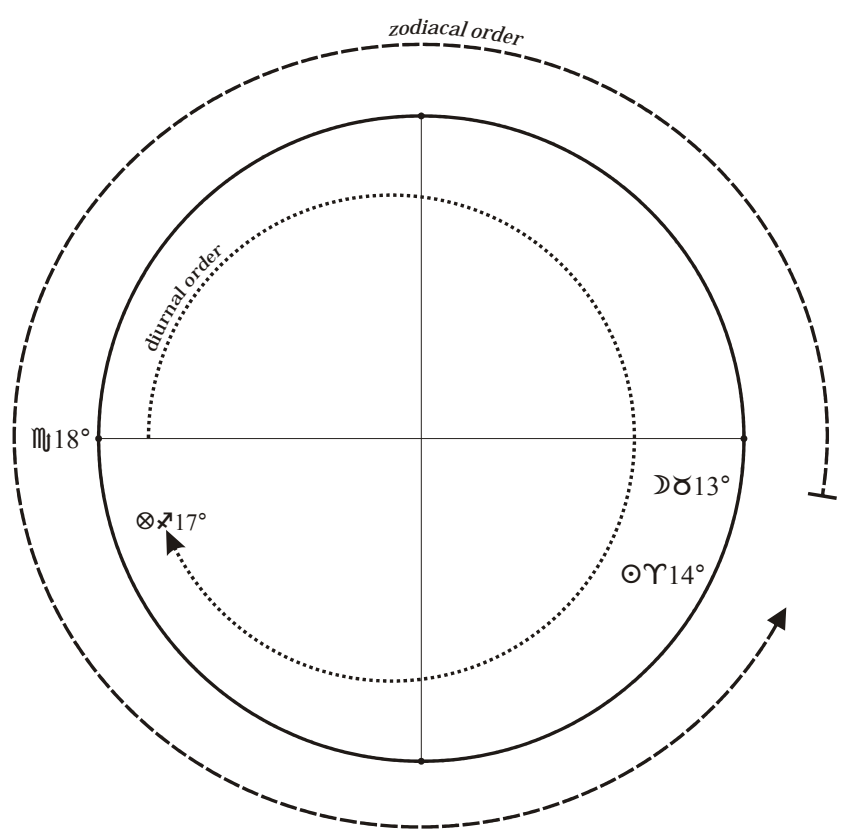

It may be, whether or not he is correct, that Pitenius is following the former interpretation; that is, he is applying the same logic to the nocturnal formula for Fortune, i.e., counting from the Moon to the Sun in zodiacal order but then reversing the order from the Ascendant. This would indeed give a position of Sagittarius $17^{\circ}$. Pitenius would then be using what, by his lights, was a nocturnal formula (reversing what he thought was the correct diurnal formula), and not acting as a precursor of what is described as the 'Ptolemaic' formula.

Another scenario is also possible. Let us take a look at evidence for additional rules about calculating the Lot of Fortune both in Valens (again citing Nechepso-Petosiris) and in a passage purported to be by Serapion of Alexandria. ${ }^{48}$ Serapion's passage may bear evidence of

${ }^{48}$ Some secondary scholarship has suggested that this Serapion was a student of
Hipparchus which would place him in the late $2^{\text {nd }}$ century/early $1^{\text {st }}$ century BCE
(A. Klotz and W. Kroll in Paulys Real-Encyclopädie der classischen Altertums-
wissenschaft, II.2 [Stuttgart, 1923], cols 1666-67; the Gundels in Astrologumena

Culture and Cosmos 
180 Calculating the Lots of Fortune and Daemon in Hellenistic Astrology

additions by a Byzantine compiler, but nevertheless it shows continuity of interest in how the Lot of Fortune should be calculated. Here is the passage:

Many times fortune becomes daemon. For [this happens] whenever the sect's luminary is in territory of the contrary sect with regard to masculine and feminine, such as the Sun by day in a feminine zodiac sign, and the Moon by night in a masculine one; and whenever the sect luminary is not eastern in the sect hemisphere. And if both the luminaries happen to be in the hemisphere under the earth and for the rest are in not in a state of familiarity, the fortune is taken from the superior (that is, from the leading) luminary to the following one. ${ }^{49}$

[Wiesbaden, 1966], pp. 113-14). David Pingree (in his scathing review of Astrologumena in Gnomon (1968), vol. 40, p. 278, as well as in The Yavanajātaka of Sphujidvaja (2 vols, Cambridge, MA/London, 1978), here vol. 2, p. 440) and Wolfgang Hübner (in Der Neue Pauly Enzyklopädie der Antike [Stuttgart/Weimar, 2001], vol. 11, p. 444), disagree. The Anonymous of 379 (who wrote a treatise on the Fixed Stars) says that Ptolemy came 'after' Serapion

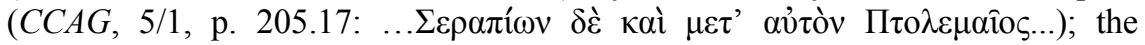

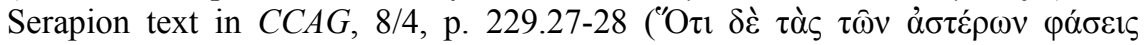

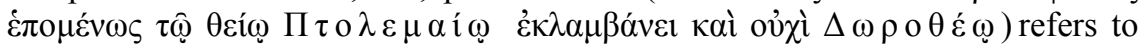
following a method of the 'divine Ptolemy' instead of Dorotheus, which would suggest that Serapion is at least contemporary with (but more likely post-dating) Ptolemy. However Pingree, who has devoted some effort to this problem of the dating of Serapion, thinks that the sentence in Serapion is an insertion of a Byzantine transcriber/compiler. In the Yavanajātaka, vol. 2, pp. 440-41, he suggests that Serapion's 'early terminology...and earlier techniques' (p. 441), plus a certain reliance on Nechepso-Petosiris and Hermes, may date him either to the $1^{\text {st }}$ century BCE or the $1^{\text {st }}$ century CE. Pingree also suggests that the $C C A G$, $8 / 4$ fragments from which our passage under discussion is taken were gathered by a Byzantine compiler and should be classified as Pseudo-Serapion. I do not intend to get into a discussion about the origins of this passage; I only want to show that it brings up continuing discussion of the calculation of the Lots of Fortune and Spirit, whether it is of Byzantine origin or not (the techniques expressed in these fragments are attested in more securely dated earlier authors).

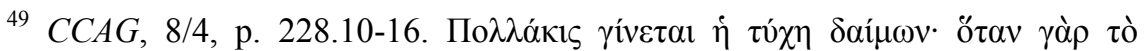

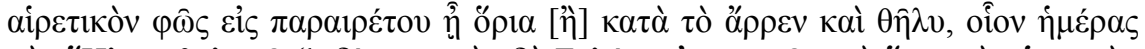

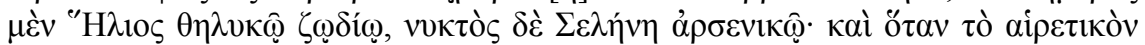

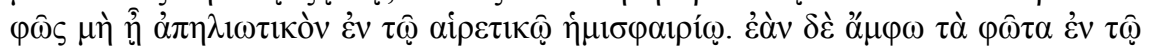


Let us take a closer look at the phrases in this passage which are pertinent to this discussion: The first is the phrase 'Many times fortune becomes daemon.' Clearly this must refer to the Lots of Fortune and Daemon. The spirit, if not the letter, of this phrase can be seen in other Hellenistic astrologers. Rhetorius, for example, in his 'Tabular Investigation', remarks that

...if the Lot of Fortune and its lord happen to be well [placed], but the Lot of Daemon and its lord happen to be badly [placed] and beheld by malefics, they result in banishment for the nativity, especially for a nocturnal nativity, on account of the Ptolemaic Lot of Fortune actually being the Lot of Daemon (my italics). ${ }^{50}$

Valens writes in a similar vein in Book IV, 4.5-7, where he lays out criteria in which one lot will replace the other in interpretation:

In fact many times, when the Lot of Fortune or its lord have fallen astray, ${ }^{51}$ the Lot of Daemon apportions things to do with both body and actions; and likewise also Fortune will apportion both, when the Lot of Daemon or

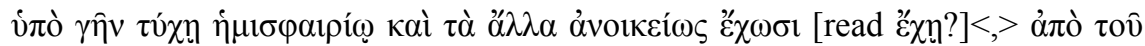

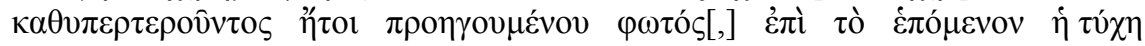
$\lambda \alpha \mu \beta \alpha ́ v \varepsilon \tau \alpha$. Thanks to Giuseppe Bezza, Stephan Heilen and Susanne Denningmann for help with this translation. Bezza provided a variant text

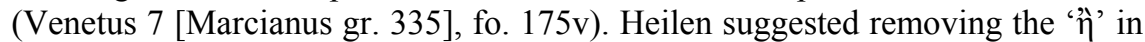
the second clause, and he and Denningmann pointed out that the comma inserted by Cumont as editor of the $C C A G$ version ought probably to be omitted. I suggest a comma insertion after $\check{\varepsilon}^{\prime} \chi \omega \sigma \mathrm{l}$ (which, since it goes with the neuter plural ' $\varphi \hat{\omega} \tau \alpha$ ', ought to be ' $\varepsilon \chi \chi \emptyset$ '). Note that the Greek verb $\pi \rho \circ \eta \gamma \varepsilon$ ' technical term which means 'leading' or 'preceding', i.e. moving in diurnal order, from east to west, while ह̌ $\pi$ o $\mu \alpha$ means 'following' in the order of the signs, but still moving from east to west.

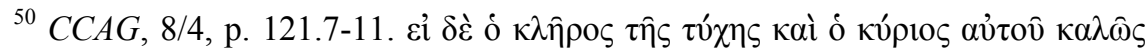

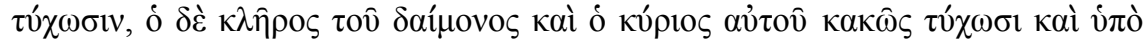

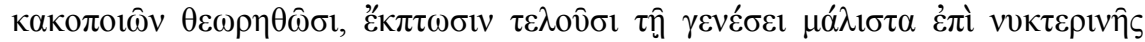

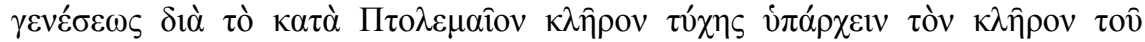

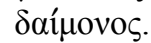

${ }^{51}$ I.e., into a cadent $\left(3^{\text {rd }}, 6^{\text {th }}, 9^{\text {th }}, 12^{\text {th }}\right)$ or 'unfortunate' place $\left(2^{\text {nd }}\right.$ or $\left.8^{\text {th }}\right)$. 
182 Calculating the Lots of Fortune and Daemon in Hellenistic Astrology

its lord have fallen astray, exactly as if it were in predomination and the House-master. Whenever Daemon and Fortune should be found in one zodiac sign, we will take things concerning the body from that same zodiac sign, but things concerning actions from the one postascending. ${ }^{52}$

A similar statement in Book III seems to be a preview of this one: 'The [Lot of] Daemon and the Hour-marking place will have the same function as the Lot [of Fortune] in the apportionment whenever the lot places or their lords should fall astray, especially when the Lot [of Fortune] cedes the apportionment to the [Lot of] Daemon. ${ }^{, 53}$

While these criteria are different from the ones given by Serapion, the concept of the two lots being able to replace each other is clearly demonstrated. The reason given is the weakness of the Lot or its lord. In Serapion, weakness of the luminary (not the lot) is the reason for changing the calculation. The luminary in the territory of the contrary sect, e.g. in a sign of a different gender, or in a weaker quadrant, are all indications of weakness.

In addition, two phrases in Serapion show similarities with another passage in Valens. The phrases are 1) '...whenever the sect luminary is not eastern in the sect hemisphere' and 2) '...if both the luminaries happen to be in the hemisphere under the earth and for the rest are not in a state of familiarity, the fortune is taken from the superior (that is, from the leading) luminary to the following one'. The passage in Valens, explaining what the 'king' (i.e. Nechepso) really means about the lot formula, is:

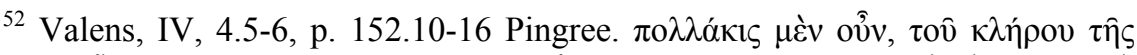

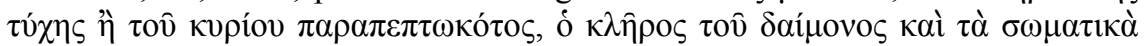

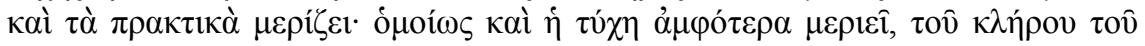

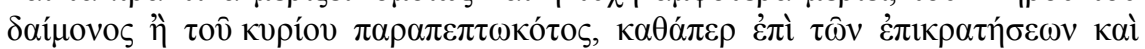

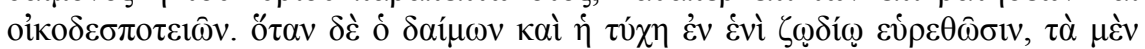

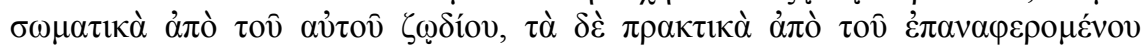
$\lambda \eta \psi o ́ \mu \varepsilon \theta \alpha$.

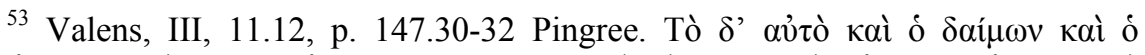

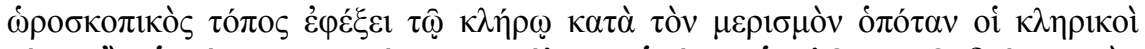

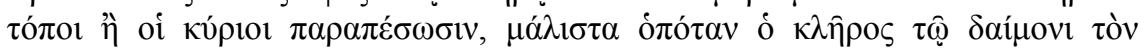

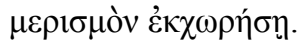

Culture and Cosmos 
...for a diurnal nativity to take from the Sun to the Moon and the equal [amount] from the Hour-marker, but for a nocturnal one in which the Moon is above the earth (that is, up until she sets), to take from her to the Sun and the equal [amount] from the Hour-marker, but after the setting from the Sun to her.... ${ }^{54}$

Both Valens and Serapion appear to be dealing with the same issue (and maybe even the same original source in Nechepso-Petosiris): whether to use the nocturnal formula for Fortune after the Moon has set. For Valens the answer, as he interprets Nechepso, is unambiguous: do not use the nocturnal formula in this case (yet his worked examples do not follow this rule). Serapion is more equivocal: the first phrase says that even if the Moon falls below the horizon, if it is eastern (in the quadrant between the I.C. and the Ascendant) it can still be the lead planet in the formula. But the meaning of his last sentence is more problematic. Plainly both luminaries are below the horizon, but what does the second phrase, 'for the rest are not in a state of familiarity' (anoikeiōs), mean? Is this familiarity by dignity? Aspect? (These are common kinds of familiarity.) Would a lack of familiarity be the wrong quadrant? Wrong sign? The answer is not clear. Even the last part of the sentence, though clear in meaning, is problematic. It seems to be an attempt to start the formula from the luminary in the strongest position (might this relate to the concept of epikratessis (predomination), ${ }^{55}$ used in finding a planet to determine length of life?). It may be that the best we can do is to say that this sentence of Serapion's is a garbled or corrupt attempt to apply the formula of Nechepso-Petosiris which is also mentioned, more cogently, by Valens in Book III, 11.4.

In any event, how might this have an impact on what Pitenius is doing in chart no. 81? Let us recall that Pitenius says those astrologers who place the lot in Libra are, out of ignorance (agnoiai), unaware of the

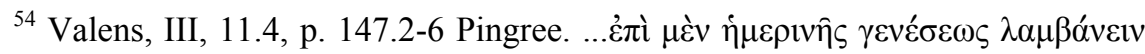

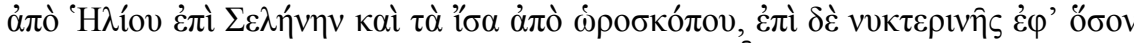

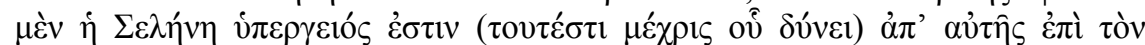

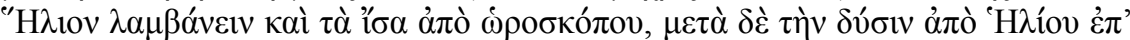
avं⿰ทेv.... We should point out that in practice, Valens does not appear to have followed this rule.

${ }^{55}$ For more on this concept see Valens, III, 1; Antiochus, Introduction, ch. 28 (29 Cumont), CCAG 8/3, p. 118.9-22; and Porphyry, Introduction to the Tetrabiblos, ch. 30 (CCAG 5/4, pp. 206-208).
}

Culture and Cosmos 
intricacies involved in deciding which formula to use for the Lot of Fortune in a nocturnal chart. ${ }^{56}$ In determining which formula to use, the informed astrologer (to use the style of Pitenius) does not stop at noticing just the sect of the chart. One must dig a little deeper, and take into account more applications of sect to the chart in general and the luminaries in particular. The more informed know that one must consider whether the luminaries are properly placed.

This chart is nocturnal. The Moon is the sect luminary. Is the Moon properly placed? It is in a nocturnal, feminine sign in a nocturnal chart, and also in the sign of its exaltation, Taurus. So far, so good. The Moon however, as the sect luminary, is below the horizon, ${ }^{57}$ in the western quadrant of the nocturnal hemisphere. Both for Valens (in theory) and for Serapion, this would require a change of formula. So in using the diurnal formula for Fortune here, perhaps Titus Pitenius is using the same kind of intepretive skill which Valens and to a lesser extent, Serapion, are employing for the calculation of the Lot of Fortune. In addition, we could also note that, since the text does show another lot (which others call the Lot of Daemon), this effectively becomes a precursor of Serapion's 'Fortune becoming Daemon'.

What are the larger implications of this zeal to use the 'correct' formula? We may find some answers in the importance of predicting life expectancy in ancient astrology.

\section{The Lot and Length of Life?}

Both the Lots of Fortune and Daemon are derived from the positions of the Sun and Moon. The luminaries and the Lot of Fortune appear in astrological techniques on finding the length of life from the chart. We see examples of this in Ptolemy and in Valens (their techniques are different, however). Ptolemy allows the Lot of Fortune to be an aphetic point $-\mathrm{a}$ 'releasing' point (aphetēs) ${ }^{58}$ from which length of life can be

\footnotetext{
${ }^{56}$ As far as I know, there is no controversy in extant literature or charts about using only the diurnal formula in a diurnal chart. The controversy is solely on whether or not to use a diurnal formula in a nocturnal chart.

${ }^{57}$ Antiochus/Rhetorius, Serapion and Valens all say that diurnal planets rejoice above the horizon in the daytime, but noctural planets rejoice above the horizon at night.

${ }^{58}$ The aphetēs has been traditionally understood as a kind of starting point, e.g. Bouché-Leclercq, L'astrologie grecque, p. 415: 'points de départ'; Greek
} 
determined. We have already seen that Ptolemy used only the diurnal formula for the Lot, calling it a 'lunar horoscope' (III, 11.5, p. 206.587593 Hübner). (However, this effectively ensures that the Lot of Daemon is used in nocturnal charts.)

Hephaestio also takes up this question in his section on length of life (II, 11 of his Apotelesmatika), following Ptolemy, but also making reference to Nechepso and Petosiris and the same difficult passage we have discussed above. Hephaestio appears to be supporting Interpretation \#1 of Nechepso-Petosiris (see Figure 3a), but this passage, unfortunately, is in poor shape in the manuscript(s), and Pingree has done some rather extensive restoration, including the crucial sentence supporting Interpretation $\# 1 .^{59}$

Horoscopes, p. 12: 'starter'. LSJ, s.v., defines it as 'prorogator' - a term which, though technically correct, hardly conveys a meaning to the modern ear. None of

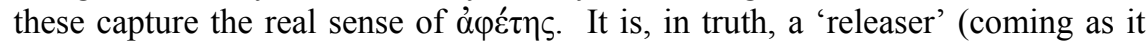
does from the verb á í $_{\mu} \mu$, literally, 'I send away from'). In the chart, planets and points which are aphetic are, in a way, like bows releasing an arrow aimed at a certain spot; which kind of bow depends on the questions asked of the chart. Aphetic points are employed in a number of systems. For more on the concept of

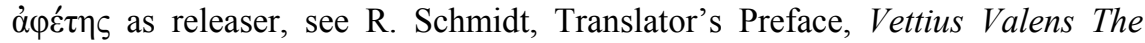
Anthology Book IV (Berkeley Springs, WV, 1996), pp. xiii-xvi.

${ }^{59}$ Hephaestio, II, $11.23-25$, p. 120.17-27 Pingree. '...the Lot of Fortune (one must $<$ take $>$ at night [by] extending the equal of the interval from the Sun to the Moon from the $<$ place $>$ of the Hour-marker). For he wishes in some way for it to be $<$ in comparison with the $>$ Hour-marker, as also Ptolemy himself says, that it thus will have some relationship, as the Sun has in relation to the rising horizon, $<$ the Moon also $>$ in relation to the Lot of Fortune. And that the old followers of Nechepso and Petosiris hint enigmatically in reference to its position, through casting out the interval in reverse for nocturnal births $<$ from the Moon $>$ to the

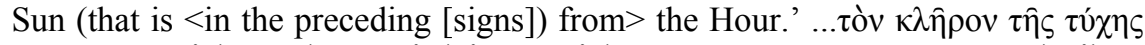

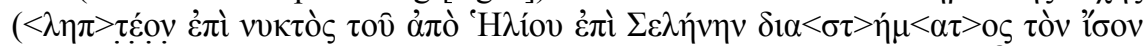

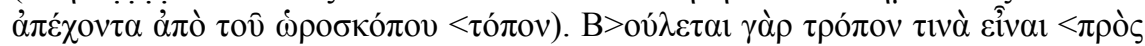

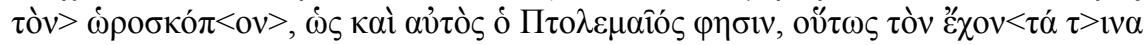

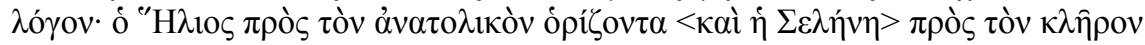

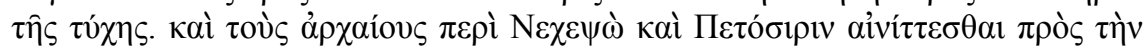

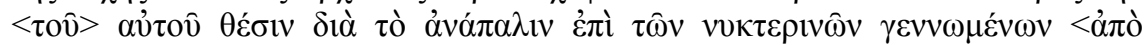

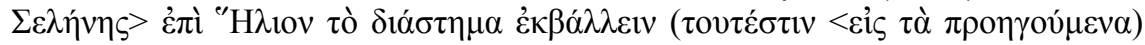

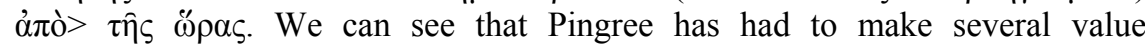
judgements here about the meaning of the passage. 
186 Calculating the Lots of Fortune and Daemon in Hellenistic Astrology

Though Manetho the astrologer, in his poem Apotelesmatika, does not mention the Lot of Fortune in his considerations on length of life, he does take the strength of the Sun and Moon into account. His general rule is to use the Sun by day and the Moon by night as the aphetēs (releaser), but he makes an exception if the luminaries are cadent or below the horizon. ${ }^{60}$ This is a circumstance also addressed by Valens and, as we have seen, by Serapion.

In Valens (III, 11.5), the ruler of the Lot of Fortune allots a certain amount of years to the native depending on its position. Valens also says, quoting Nechepso-Petosiris, that the diurnal formula is used at night when the Moon is below the horizon; but he also tells us that if the Lot or its lord 'falls astray', then 'Daemon and the Hour-marking place' can be used (III, 11.12, as discussed on p. 182). Valens makes a similar statement in Book IV, 4.5-6 (see pp. 181-82).

Valens also uses both the Lots of Fortune and Daemon as aphetic points, determining events of the native's life and circumstances of his death.

Two comments may be made here. First, the issue of which formula to use seems to arise mainly in questions of life expectancy (both for Valens and for Ptolemy, who are the main delineators of the technique). For Ptolemy, any nocturnal chart would show what other astrologers called the Lot of Daemon, not the Lot of Fortune (Rhetorius even points this out). Life expectancy requires finding the most powerful place in the chart, and the first things the astrologer looks at are the Sun and the Moon. The power of the luminary is dependent on its sect, dignity and placement in the chart. Each luminary is stronger when in its own sect: the Sun in the day, the Moon at night. The formulae for the Lot of

${ }^{60}$ R. Lopilato, ed., tr. (English) and comm., Manetho, Apotelesmatika (PhD dissertation, Brown University, Providence, 1998), III.399-415, and esp. 406-13 (pp. 74, 237): 'For whomever being born in the daytime Titan [the Sun] is seen / standing on a centrepin [angle], from that / degree begin to count out the time of life; / and in a nocturnal nativity from the degree of the Moon. / When the shining ones have declined outside the centrepins / or proceed in their headlong course / in the degrees of the lower hemisphere, then begin with that star / which

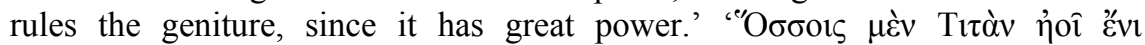

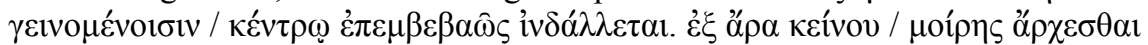

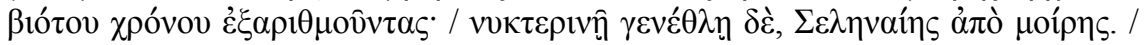

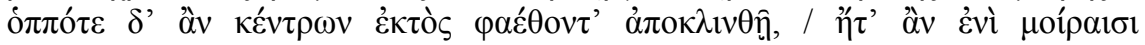

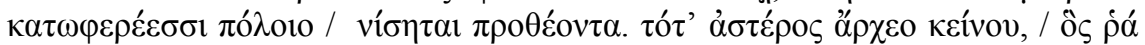

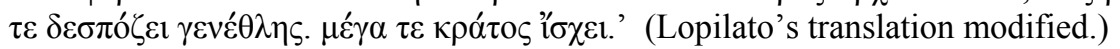


Fortune clearly try to take this into account, in that the planet from which the arc is calculated is the planet in sect. When we see variations in this method, they are because the sect luminary is weakened (and, of course, in practice, only the nocturnal formula is affected).

Secondly, the obvious linkage of the Lots of Fortune and Daemon (mathematically, astrologically and culturally) may have suggested that both were valuable in determining lifespan from the birthchart. If consistent results could not be obtained by using only one lot and one lot formula, the other(s) were brought in as needed - thus the importance of using the correct formula and, especially for an astrologer like Valens, the emphasis on the Lot of Daemon in other contexts. In the final analysis, here is yet another instance of the importance and utility, via multivalency, of the Lots of Fortune and Daemon in astrological interpretation. 